\title{
COMMISSIONING OF NEW INJECTION LINE AT INR PROTON LINAC
}

\author{
S. K. Esin, L. V. Kravchuk, A. I. Kvasha, A. N. Mirzojan, P. N. Ostroumov, \\ O. D. Pronin, V. A. Puntus, G. V. Romanov, S.I. Sharamentov, V. L. Serov, A. A. Stepanov, \\ A.V. Vasyuchenko, R. M. Vengrov \\ Institute for Nuclear Research RAS, 117312 Moscow
}

\begin{abstract}
An essential reconstruction of the injection line has been carried out in the INR linac. The original LEBT was designed to inject $750 \mathrm{keV}$ proton and $\mathrm{H}^{-}$beams simultaneously into the Alvarez tank. It included a section downstream of the merging magnet, where two beams are transported simultaneously. In order to improve reliability of the high voltage transformers as well as to increase average current of the accelerated beam a decision has been taken to insert a booster RFQ downstream of the merging magnet. The 198.2 MHz RFQ has been designed to accelerate hydrogen ions from $400 \mathrm{keV}$ to $750 \mathrm{keV}$. For the transportation of $400 \mathrm{keV}$ beam from HV injector to the RFQ entrance the old part of the LEBT is used. A $345 \mathrm{~mm}$ space between RFQ and DTL contains a buncher with the effective voltage of $110 \mathrm{kV}$, four electromagnet quadrupole lenses and two boxes for beam diagnostics. The results of the commissioning of the new injection system are reported.
\end{abstract}

\section{INTRODUCTION}

The operational experience at the INR linac [1] has shown that the electrical reliability of the $750 \mathrm{kV}$ pulsed transformer and accelerating tube is not sufficient at higher repetition rate (above $50 \mathrm{~Hz}$ ). Therefore a booster RFQ to upgrade the beam energy from $400 \mathrm{keV}$ to 750 $\mathrm{keV}$ has been proposed and developed [2]. The reduction of the pulse transformer voltage allows us to increase the beam pulse duration from $80 \mu$ s to $150 \mu$ s being operated below the saturation of the core. The duty factor and the average beam current of the linac are increased proportionally.

Historically the injection line (LEBT) of the linac is divided to three sections, the last one is a channel where the hydrogen ions are transported simultaniously. The new RFQ and an additional equipmernt for the beam matching and diagnostics have been designed to install on the third section of the LEBT (see Fig.1). A $45 \mathrm{~mm}$ diameter collimator, a wire scanner and a solenoid are placed upstream of the RFQ. Due to the limited space and reletively high energy of the beam being injected the adiabatic capture in the RFQ could not be provided. To improve the longitudinal capture an additional buncher B400 has been foreseen in front of the RFQ. The matching section between the RFQ and DTL must be designed as short as possible to provide the efficient capture of the RFQ beam with relatively large momentum spread into the DTL. That section length is only $345 \mathrm{~mm}$. A design task to place a large number of the matching and diagnostic equipment in the space between the RFQ and DTL has been successfully solved.

The equipment manufacturing and installation was finished last fall. During the beam production shifts in November-December 1998 the RFQ and matching section were commissioned.

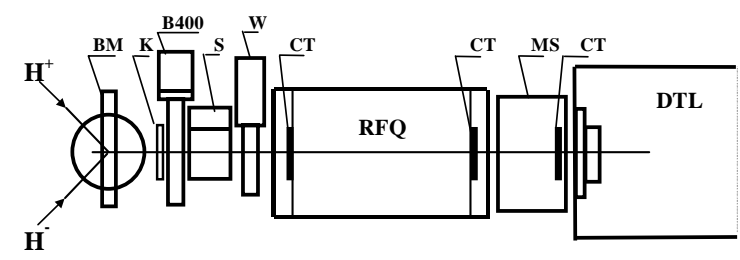

Figure 1: Layout of the LEBT containing the new equipment.

A description of the main equipment, their tuning and first operations with the new LEBT are given below.

\section{RFQ CAVITY}

The main parameters of the RFQ are shown in Table 1[2].

Table 1: Basic parameters of the RFQ.

\begin{tabular}{|l|c|}
\hline Operating frequency & $198.2 \mathrm{MHz}$ \\
\hline Input energy & $400 \mathrm{keV}$ \\
\hline Output energy & $750 \mathrm{keV}$ \\
\hline Energy spread (full width, $100 \mathrm{~mA}$ ) & $4.6 \%$ \\
\hline Phase spread (full width, $100 \mathrm{~mA}$ ) & $70^{\circ}$ \\
\hline Intervane voltage & $150 \mathrm{kV}$ \\
\hline Mean bore radius ( $\mathrm{r}_{0}$ ) & $8 \mathrm{~mm}$ \\
\hline Aperture radius & $6.85 \mathrm{~mm}$ \\
\hline Length of the vanes & $1199 \mathrm{~mm}$ \\
\hline Cavity length & $1300 \mathrm{~mm}$ \\
\hline Inside diameter of the tank & $325 \mathrm{~mm}$ \\
\hline
\end{tabular}

A simplified assembly drawing of the RFQ cavity is shown in Fig. 2. The RFQ tank and the end covers are made of stainless steel. The inside surface of the tank is covered by $5 \mathrm{~mm}$ layer of oxygen free copper using diffusion welding technique. The tank consists of two sections. Aluminum rings are used as vacuum seals between the sections and end covers. The electrical contact is provided with pressing of inside copper layers. A roughness of the copper surface is $\sim 0.8 \mu \mathrm{m}$. The 


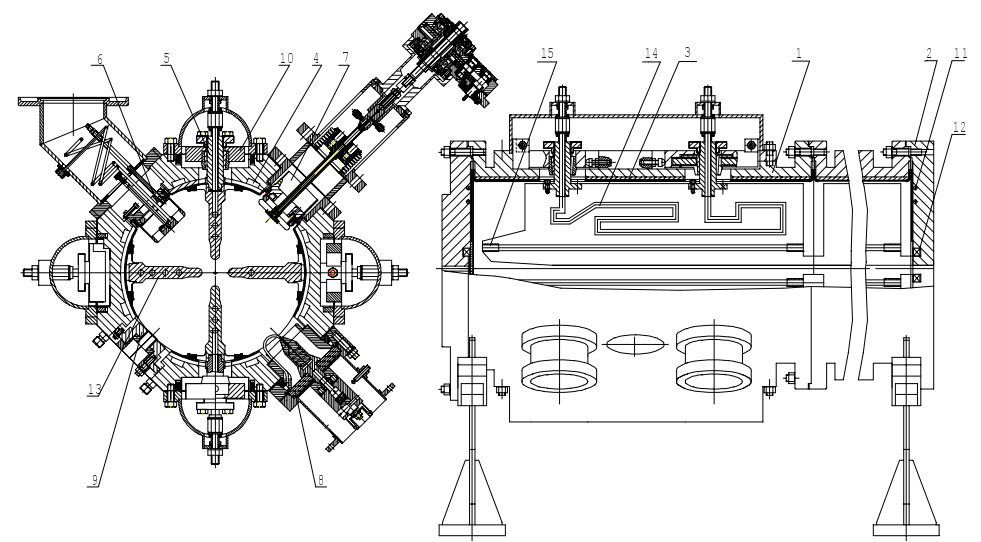

Figure 2: Simplified assembly drawing of the RFQ cavity: 1- tank body; 2- cover; 3- inner lining; 4,11,14 - cooling channel; 5- bellow unit; 6,7- tuning units; 8-rf power loop; 9- peak-up loop port; 10- adjustment plate; 12beam current transformer; 13-vane; 15- target hub.

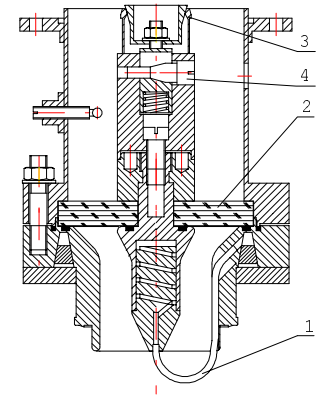

Figure 4: RF power coupling loop: 1- loop; 2- quartz window; 3- collet connector; 4- clamping screw.

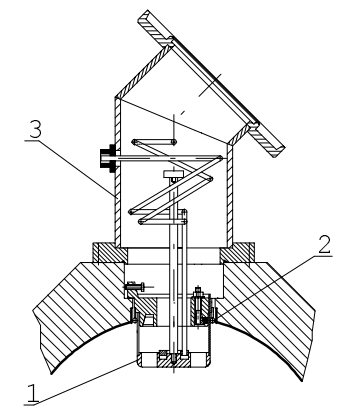

Figure 5: Tuning unit: 1- piston; 2-rf contact; 3-pumping tube.

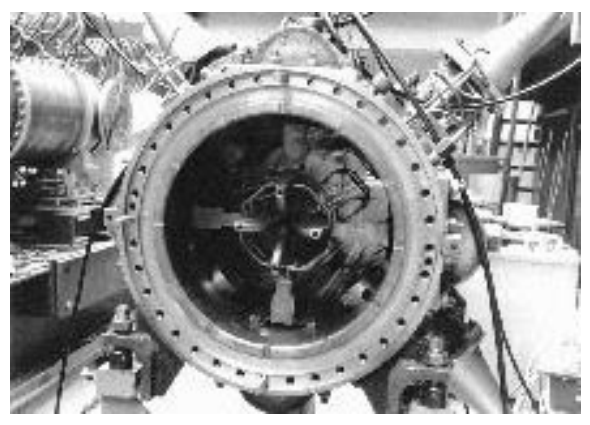

Figure 6: The front end view of the RFQ.

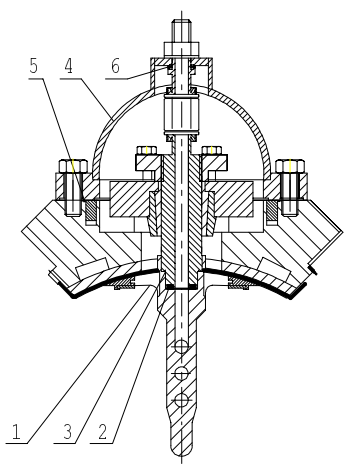

Figure 3: Vane alignment unit.

measured Q-value of the RFQ cavity is 5670. Fig. 3 shows the vane alignment unit covered by vacuum cap (4). The cooling water enters into the vane through the bellow. A RF contact of the vane with the inside copper surface of the tank is provided by copper foil (1). The water seal (2) is made of rubber. For the vacuum sealing of the RFQ cavity several types of material, such as indium (3), aluminum (5) and copper (6) are used. The RFQ cavity is fed by the RF power using four coupling loops (Fig. 4). The RF window (2) is made of quartz. The coupling can be adjusted by the change of the thickness of a copper seal. A VSWR at the frequency of $198.2 \mathrm{MHz}$ has been measured and found to be equal to 1.5. The cavity has eight tuning pistons with a diameter of $75 \mathrm{~mm}$ (Fig. 5). The tuning pistons are installed in the vacuum pumping ports. The half of the total number of pistons can be adjusted. Beam current transformers are mounted inside of the end covers. The cavity is equipped with eight $160 \mathrm{l} / \mathrm{s}$ titanium pumps. A front view of the RFQ is shown in Fig. 6.

\section{RFQ POWER SUPPLY}

The four-stage 198.2 MHz power amplifier, similar to the standard DTL tank one, feeds the RFQ cavity. A RF power divider by 4 is installed in the output of $300 / 130$ mm coaxial feeder. The divider is a quarter wavelength transformer with the characteristic resistance of $25 \Omega$. Four 25 m coaxial cables PK-50-44-17 are connected to the divider. The cable withstands up to $1 \mathrm{MW}$ pulsed power at the average power of $3.5 \mathrm{~kW}$ at the frequency of $200 \mathrm{MHz}$. The divider reliability has been tested by the installation of the similar device in the output of four cables, which has been connected to matched load. Up to $500 \mathrm{~kW}$ peak power in $220 \mu$ s pulse length at the repetition rate of $100 \mathrm{~Hz}$ has been successfully transported into the load. All of four cables have been connected to the RFQ by means of a special angular sockets. An extra attention has been paid to the equalizing of the electrical length of the cables. The cable lengths have been chosen on the basis of capacity measurements with accuracy of $0.3 \mathrm{pF}$. The final determination of the 
cable lengths has been made on the base of low level phase measurements with the precision of $\sim 5^{\circ}$.

The conditioning of the RFQ cavity has been performed at the vacuum pressure of $1 \cdot 10^{-6}$ Torr by smooth rise of average and peak rf power at the pulse duration of 50 , $100,220 \mu \mathrm{s}$ and repetition rate of $10,50,100 \mathrm{~Hz}$. The pulsed power of $280 \mathrm{~kW}$ has been gained during 60 hours of conditioning.

The tank, the end covers, coupling loops and tuners are cooled with deionized water from the DTL water-cooling circuit. The resonant frequency is controlled by the water temperature which flows through the vanes. For this purpose a $24 \mathrm{~kW}$ electrical heater is used. The heater current is controlled either by temperature gauge or by the phase difference signal taking from the RFQ measuring loop and from capacitor probe installed in one of the RFQ angular sockets. A temperature coefficient is about 50 $\mathrm{kHz}$ per $1^{\circ} \mathrm{C}$. The operating temperature of the water in the RFQ tank is about $23^{\circ} \mathrm{C}$. The water temperature in the vanes is higher by $2.5^{\circ} \mathrm{C}$.

\section{RFQ-DTL MATCHING SECTION}

The matching section (Fig. 7) is designed to match the 6D emittance of the RFQ beam to the DTL acceptance. An effective voltage of $110 \mathrm{kV}$ on the buncher B-750 gap is required to match the beam longitudinal emittance. Four quadrupole lenses Q1...Q4 with maximum gradients of $4.8 \ldots 3.8 \mathrm{kGs} / \mathrm{cm}$ and $8 \ldots 14 \mathrm{~mm}$ radius of aperture are used for the beam transverse matching. The first diagnostic box is located downstream of the lens Q1 (Fig. 7). It contains two slits in $X$ and $Y$ axis and a harp. Another diagnostic box is placed downstream of the lens Q3. It is equipped with multistrip collector, variable collimator, current transformer and a vacuum valve. A general side view of the matching section is shown in Fig. 8.

\section{COMMISSIONING RESULTS}

The lower beam energy from the injector results in increase of the full unnormalized beam emittance from 10 $\pi \cdot \mathrm{cm} \cdot \mathrm{mrad}$ to $15 \pi \cdot \mathrm{cm} \cdot \mathrm{mrad}$. The transmission of the beam current along the whole LEBT has not optimised yet. Therefore only $28 \%$ of the $120 \mathrm{~mA}$ total current is transported to the RFQ entrance. The proton beam current at the output of the RFQ is $\sim 25 \mathrm{~mA}$. A $12.5 \mathrm{~mA}$ peak current beam has been accelerated along the whole linac without any bunchers. The total particle losses above the $20 \mathrm{MeV}$ part of the linac are eqaul to $\sim 0.1 \%$. For this moment the average current of the beam is sufficient for the users. We believe that the peak current of the accelerated beam can be increased up to $25 \mathrm{~mA}$ by the help of careful tuning of the LEBT, bunchers and matching quadrupoles.

\section{CONCLUSION}

The installation and commissioning of the RFQ has increased the average current and improved the reliability

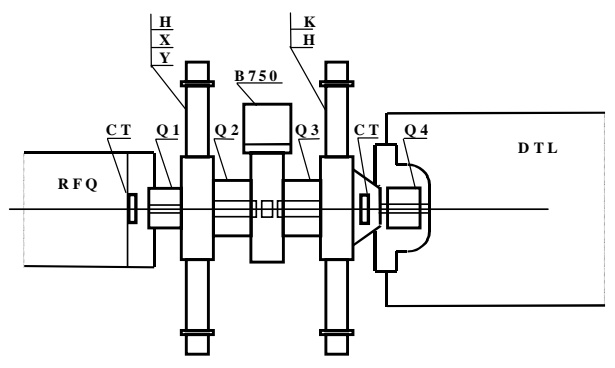

Figure 7: The RFQ-DTL matching section.

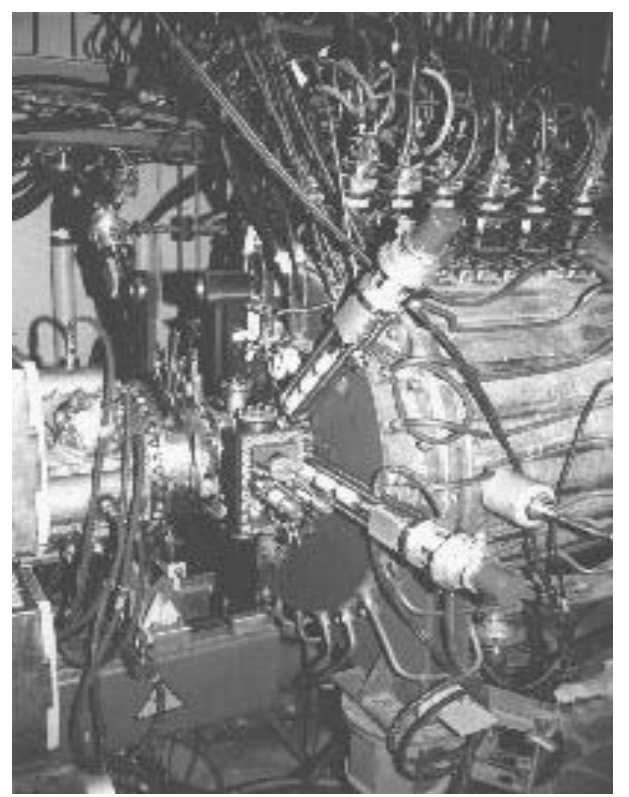

Figure 8: The matching section.

of the linac operation. There are reserves for the further increase of the beam current by the help of careful tuning of the LEBT and matching section.

\section{ACKNOWLEDGMENTS}

Authors express their gratitude to the linac staff as well as to specialists of ITEP (Moscow), IHEP (Protvino) and Tambov plant "Komsomolets" taking part in development and manufacturing of the new LEBT.

\section{REFERENCES}

[1] S. K. Esin, et al, "Commissioning/Operation of the Moscow Meson Factory Linac", Proc. of the 1994 Linac Conf., Tsukuba, p. 31. [2] A. Andreev, et al, "Development of RFQ Accelerator for the MMF Linac", IEEE PAC91, San Francisco, vol. 5, p. 3109. 